\title{
Vibro-Fluidized Bed Drying of Pumpkin Seeds: Assessment of Mathematical and Artificial Neural Network Models for Drying Kinetics
}

\author{
Priyanka Dhurve $\mathbb{D}^{1},{ }^{1}$ Ayon Tarafdar $\mathbb{D}^{1},{ }^{1,2}$ and Vinkel Kumar Arora ${ }^{1}{ }^{1}$ \\ ${ }^{1}$ Department of Food Engineering, National Institute of Food Technology Entrepreneurship and Management, Kundli, \\ Sonipat 131 028, Haryana, India \\ ${ }^{2}$ Livestock Production and Management Section, ICAR-Indian Veterinary Research Institute, Izatnagar, Bareilly 243 122, \\ Uttar Pradesh, India \\ Correspondence should be addressed to Vinkel Kumar Arora; vinkelarora17@gmail.com
}

Received 19 September 2021; Accepted 21 October 2021; Published 8 November 2021

Academic Editor: Igor Tomasevic

Copyright (c) 2021 Priyanka Dhurve et al. This is an open access article distributed under the Creative Commons Attribution License, which permits unrestricted use, distribution, and reproduction in any medium, provided the original work is properly cited.

\begin{abstract}
Pumpkin seeds were dried in a vibro-fluidized bed dryer (VFBD) at different temperatures at optimized vibration intensity of 4.26 and $4 \mathrm{~m} / \mathrm{s}$ air velocity. The drying characteristics were mapped employing semiempirical models and Artificial Neural Network (ANN). Prediction of drying behavior of pumpkin seeds was done using semiempirical models, of which, one was preferred as it indicated the best statistical indicators. Two-term model showed the best fit of data with $R^{2}-0.999$, and lowest $\chi^{2}-1.03 \times 10^{-4}$ and MSE $7.55 \times 10^{-5}$. A feedforward backpropagation ANN model was trained by the Levenberg-Marquardt training algorithm using a TANSIGMOID activation function with 2-10-2 topology. Performance assessment of ANN showed better prediction of drying behavior with $R^{2}=0.9967$ and MSE $=5.21 \times 10^{-5}$ for moisture content, and $R^{2}=0.9963$ and $\mathrm{MSE}=2.42 \times 10^{-5}$ for moisture ratio than mathematical models. In general, the prediction of drying kinetics and other drying parameters was more precise in the ANN technique as compared to semiempirical models. The diffusion coefficient, Biot number, and $h_{m}$ increased from $1.12 \times 10^{-9} \pm 3.62 \times 10^{-10}$ to $1.98 \times 10^{-9} \pm 4.61 \times 10^{-10} \mathrm{~m}^{2} / \mathrm{s}, \quad 0.51 \pm 0.01$ to $0.60 \pm 0.01$, and $1.49 \times 10^{-7} \pm 4.89 \times 10^{-8}$ to $3.10 \times 10^{-7} \pm 7.13 \times 10^{-8} \mathrm{~m} / \mathrm{s}$, respectively, as temperature elevated from 40 to $60^{\circ} \mathrm{C}$. Arrhenius's equation was used to the obtain the activation energy of $32.71 \pm 1.05 \mathrm{~kJ} / \mathrm{mol}$.
\end{abstract}

\section{Introduction}

Pumpkin belongs to the Cucurbitaceae family and is broadly grown around the warmer regions across the world. The worldwide production of pumpkin, squash, and gourd was 27 million tons (MT) in 2017. India is the second-largest producer, with about $20 \%$ (5.56 MT) of the total worldwide production [1]. Pumpkin contains flesh (72-76\%), byproduct peel $(2.6-16 \%)$, and seeds $(3.2-4.4 \%)$ [2]. The pumpkin processing industry separates useful parts of the fruit from by-products, which constitute peel and seeds [3]. Pumpkin seeds are a vital source of bioactive components such as fats, essential proteins, vitamins, phytosterols, squalene, tocopherols, and carotenoid pigments $[4,5]$. It is consumed as snack food in several countries, and its oil is generally used in cooking and for pharmaceutical applications. The pumpkin seeds have high moisture; therefore, they are highly susceptible to microbial spoilage and chemical alteration [6].

The demand for pumpkin seeds is increasing on account of their high nutritional and functional properties. This is likely to encourage investigations on the effects of postharvest processing and industrial by-product utilization to prevent degradation of quality. Drying is the most appropriate technique to stop microbial spoilage and to prolong the storage of such seeds [7]. Furthermore, it also reduces transportation and storage costs. However, physical and nutritional changes can occur in food materials including 
some quality characteristics, such as texture, color, and flavor [8]. Thus, the selection of proper drying techniques is a particularly important step in food processing.

A mechanical vibration-assisted fluidized bed is also a potential advanced drying technique to improve the fluidization of such particles [9]. The electrical energy consumed by blower and vibration motor in a vibro-fluidized bed dryer (VFBD) has been reported to be around $55 \%$ of the electrical energy of the blower in FBD [10]. Furthermore, by inducing vibration to the fluidized bed, homogeneous temperature circulation can be achieved [11], agglomeration of solid particles can be prevented and the fluidization velocity and pressure drop can be reduced $[12,13]$.

In drying, heat and mass transfer take place at the same time due to its complexity. Therefore, optimization of drying process conditions is important, and for this, mathematical modeling is an exceptional tool [14]. Moreover, modeling is applied to find out the drying time and general nature of drying. To design and select dryers, knowledge of drying behavior is very important. There are several studies reported in the literature to predict or develop the most suitable mathematical model for drying kinetics. Generally, to predict the drying behavior of agricultural commodities different mathematical models, namely, empirical, semiempirical, and theoretical, are used. In most of the drying experiments, empirical models validate the exceptional fitting of data but overlook the basics of the drying processes. While theoretical models justify diffusion mechanism or heat and mass transfer mechanism [15], there are several investigations on mathematical modeling of pumpkin seeds drying kinetics for natural and forced convection solar dryer [6], solar tunnel dryer [16], tray drying [17], fluidized bed drying [17-20], and infrared dryer [21]. However, no study was found for pumpkin seed drying using a vibro-fluidized bed dryer.

The drying of biological samples is a complex method and on occasions, may not be explained using traditional models. For that purpose, a neural network approach was also attempted for this study considering the novel nature of the drying process. Artificial neural networks (ANN) are a machine learning method applied to predict intricate correlations among input and output conditions of drying and nonlinear problems [22]. Many researchers used ANN to explain moisture content, rate of drying, moisture ratio, effective diffusivity, and specific energy consumption for different agriculture products [23-25]. Alvarez et al. [26] successfully used ANN to correlate the heat and mass transfer parameters and vibration parameters (amplitude, frequency, and vertical motion) for poppy seeds dried in a vibrated fluidized bed dryer. Kumar et al. [27] used a feedforward backpropagation ANN model to predict the moisture ratio by feeding drying temperature and time as input parameters. According to our intensive literature search, no work has been reported on the modeling of drying kinetics of pumpkin seeds in a VFBD by ANN and its comparison with semiempirical drying models to the best of our knowledge. Moreover, information on the mass transfer parameters for pumpkin seed drying using VFBD is not available. Such parameters are useful in designing drying equipment and optimizing industrial drying processes and hence were taken up in this investigation.

Therefore, the aim of the current work is to perform pumpkin seeds drying in a VFBD at various drying parameters along with the determination of drying and mass transfer parameters. The study also deals with the prediction and comparison of the drying behavior of pumpkin seeds using semiempirical modeling and ANN.

\section{Materials and Methods}

2.1. Sample Preparation. Pumpkins (Cucurbita maxima) were procured from the market of Narela, New Delhi, India, during the summer season. The pumpkins were cut in half followed by manual removal of the seeds. Undeveloped seeds were removed and the seeds exhibiting the same size were washed with deionized water and pressed in a sieve, to remove the stringy pulp. The washed seeds were stored in low-density polyethylene (LDPE) airtight bags at $-10^{\circ} \mathrm{C}$ and were subjected to drying treatment within $24 \mathrm{~h}$ of storage. Hot-air oven method was used to estimate initial moisture content at $105^{\circ} \mathrm{C}$ for $24 \mathrm{~h}$ [28]. All readings were replicated thrice for accuracy.

2.2. Experimental Setup. An electrical power-operated vibro-fluidized bed dryer was fabricated at the Department of Food Engineering, NIFTEM, Haryana, India, as depicted in Figure 1. The components and specifications of VFBD are presented in Table 1.

2.3. Vibration Intensity. The vibration intensity $(\Gamma)$ was calculated using the following equation [29]:

$$
\Gamma=\frac{A(2 \pi f)^{2}}{g},
$$

where $A$ is the amplitude, $\mathrm{mm} ; \mathrm{g}$ is the acceleration due to gravity, $\mathrm{mm} / \mathrm{s}^{2}$; and $f$ is the frequency of vibration, $\mathrm{Hz}$. Pakowski et al. [30] recommended the optimum range of $\Gamma$ for proper structure of bed and drying rate as 1-6.

2.4. Drying Experiments. The experiments were conducted at different conditions as shown in Table 2. Air velocity selected for fluidization was $4 \mathrm{~m} / \mathrm{s}$ as given by Kaveh et al. [7] for squash seeds. Before each experiment, the three dryers were run for $30 \mathrm{~min}$ in no-load condition to accomplish the chosen operating parameters of the drying chamber. For drying, pumpkin seeds of approximately $200 \mathrm{~g}$ were placed on the perforated sieve of the VFBD. The weight of moisture was recorded at 5 min intervals. Drying was continued until $0.007-0.009 \mathrm{~kg} \mathrm{H}_{2} \mathrm{O} / \mathrm{kg}$ dm moisture remained in the sample, which is the safe storage moisture content for high-oil-content seeds. The dried samples were cooled in desiccators at an ambient temperature $\left(27^{\circ} \mathrm{C}\right)$ for $15 \mathrm{~min}$ and then filled in LDPE bags for additional investigations. 


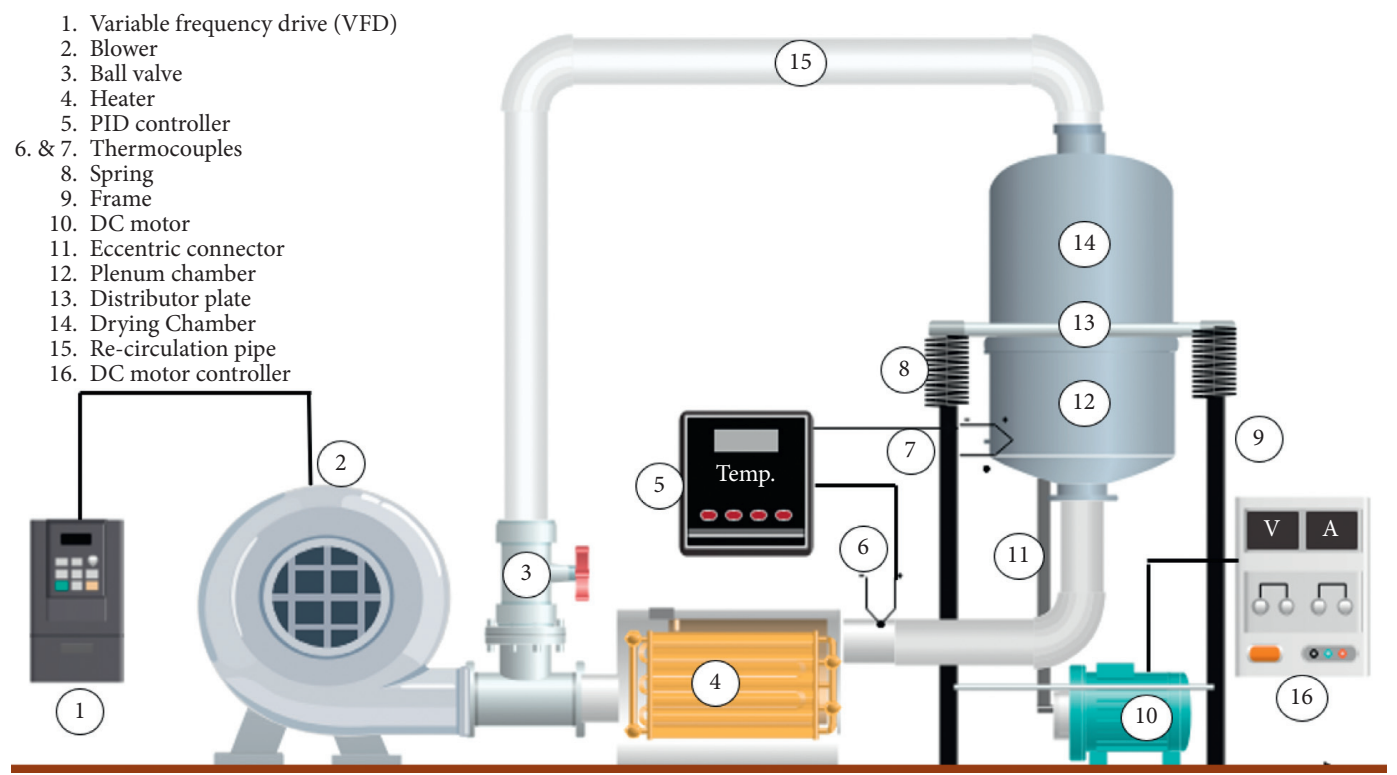

Figure 1: Schematic diagram of the vibro-fluidized bed dryer.

Table 1: Design specifications of the vibro-fluidized bed dryer.

\begin{tabular}{|c|c|}
\hline Components & Specifications \\
\hline \multirow{3}{*}{ Drying chamber } & Dimension $=0.35 \mathrm{~m} \times 0.40 \mathrm{~m}($ diameter $\times$ height $)$ \\
\hline & Volume $=0.0384 \mathrm{~m}^{3}$ \\
\hline & Capacity $=10-15 \mathrm{~kg}$ per drying cycle \\
\hline Plenum chamber & Dimension $=0.35 \mathrm{~m} \times 0.25 \mathrm{~m}($ diameter $\times$ height $)$ \\
\hline Distributor plate & $\begin{array}{c}\text { Dimension }=0.35 \mathrm{~m} \text { diameter and } 0.0002 \mathrm{~m} \text { aperture diameter } \\
1 \mathrm{HP}\end{array}$ \\
\hline \multirow[t]{2}{*}{ Vibration motor (DC) with eccentric wheel blower } & 2HP with $2800 \mathrm{rpm}-3$ phases \\
\hline & Air flow rate $=650-670 \mathrm{~m}^{3} / \mathrm{h}$ \\
\hline \multirow{2}{*}{ Variable frequency drive (delta: VFD015S21D, US) } & $1.5 \mathrm{~kW}-1$ phase \\
\hline & Frequency $=0-60 \mathrm{~Hz}$ \\
\hline Heating chamber & $0.50 \times 0.50 \times 0.40 \mathrm{~m}$ \\
\hline Heater & 1 coil type $=2 \mathrm{~kW}$ and 4 fins type $=4 \mathrm{~kW}$ \\
\hline PID controller (Instron IN- 312 and KRITMAN GHC-100, India) & $30^{\circ} \mathrm{C}$ to $600^{\circ} \mathrm{C}$ \\
\hline Temperature measurement & PT-100 and k-type thermocouple \\
\hline \multirow{4}{*}{ Hot-air anemometer (Mextech AM 4208, Mextech, India) } & Sensor $=0.0072 \mathrm{~m}$ \\
\hline & Air velocity range $=0.4-45 \mathrm{~m} / \mathrm{s}$ \\
\hline & Air temperature range $=0-50^{\circ} \mathrm{C}$ \\
\hline & Air flow $=0-9999 \mathrm{~m}^{3} / \mathrm{min}$ \\
\hline
\end{tabular}

TABLE 2: Experimental parameters for VFBD.

\begin{tabular}{lc}
\hline Operating parameters & VFBD \\
\hline Initial moisture content $\left(\mathrm{kg} \mathrm{H} \mathrm{H}_{2} \mathrm{O} / \mathrm{kg}\right.$ dry matter$)$ & $1.442 \pm 0.082$ \\
Air temperature $\left({ }^{\circ} \mathrm{C}\right)$ & 40,50, and 60 \\
Air velocity $(\mathrm{m} / \mathrm{s})$ & 4 \\
Vibration intensity & $4.29(\mathrm{~A}=10 \mathrm{~mm}$ and $f=10.3 \mathrm{~Hz})$ \\
Bed height $(\mathrm{cm})$ & Thin layer \\
Ambient temperature $\left({ }^{\circ} \mathrm{C}\right)$ & $27-30$ \\
Relative humidity $(\%)$ & $45-50$ \\
\hline
\end{tabular}

2.5. Drying Kinetics and Mathematical Modeling. The moisture ratio during drying was computed using the standard equation (Babar et al., 2020).
The experimental data of drying of pumpkin seeds were fitted to six thin-layer drying models as shown in Table 3. The parameters of the models were estimated using a 
nonlinear regression procedure. For selecting the most appropriate model to depict thin-layer drying, determination coefficient $\left(R^{2}\right)$, chi-square $\left(\chi^{2}\right)$, and mean square error (MSE) were used. These parameters were calculated using standard equations $[18,31]$.

2.6. ANN Modeling. ANN mimics the functionality of a neuron in the human brain. It adapts to new knowledge and identifies patterns in fuzzy and inaccurate data. In this work, the modeling of experimental data was also done by a multilayer FFBP neural network using the neural network toolbox of MATLAB v.2012a (MathWorks Inc., USA). The ANN model was provided with different air temperature and drying time data as input, while MC and MR were given as output (supervised training) with one hidden layer, to reduce the complexity of the model. The best ANN infrastructure for accurate drying data prediction was done on a trial-and-error basis. There were numerous backpropagation training algorithms such as scaled conjugate gradient (SCG), Polak-Ribière conjugate gradient (CGP), BFGS quasi-Newton (BGF), Levenberg-Marquardt (LM), resilient (Rprop), gradient descent (GDX) backpropagation, etc. [32]. From these, the Levenberg-Marquardt training algorithm (TRAINLM) was used because of its previously proven efficiency in drying data prediction [33].

For model development, $70 \%$ was used for training and $30 \%$ of the remaining data for testing and validation, respectively. The TANSIGMOID activation function was exercised to correlate the signal of input and output of each layer and to decrease the processing time. As proposed by Dorofki et al. [34], as an approximation function, the PURELIN transfer function was applied to the output layer. The number of iterations was limited to 1000 to reduce the validation time while ensuring proper model termination (attainment of error goals). As for performance indicators of the model, MSE and correlation coefficient $(R)$ were recorded.

The signal received to the first HL from the input layer was expressed as follows [22]:

$$
H L_{i}=\sum_{j=1}^{n} \sum_{i=1}^{10} I_{i} w_{i j}+b_{j}
$$

The output signal of neuron can be expressed using the following equations, respectively:

$$
\begin{gathered}
H_{01}=\frac{1}{1+e^{-H_{l 1}}}+b_{1}, \\
H_{01}=\frac{e^{H_{l 1}}-e^{-H_{l 1}}}{e^{H_{l 1}}+e^{-H_{l 1}}}+b_{1} .
\end{gathered}
$$

Output layer will receive 10 signals from $10 \mathrm{HL}$, which was expressed using the following equation:

$$
O_{l 1}=\sum_{j=1}^{10} H_{o j} V_{j 1}+b_{2} \text {. }
$$

TABLE 3: Most commonly used semiempirical models for illustrating the drying kinetics of seeds.

\begin{tabular}{lc}
\hline Models & Model equation \\
\hline Page & $\mathrm{MR}=\exp \left(-k \times t^{n}\right)$ \\
Modified page & $\mathrm{MR}=\exp (-k \times t)^{n}$ \\
Newton & $\mathrm{MR}=\exp (-k \times t)$ \\
Henderson and Pabis & $\mathrm{MR}=a \times \exp (-k \times t)$ \\
Two-term & $\mathrm{MR}=a \times \exp (-k \times t)+b \times \exp \left(-k_{0} \times t\right)$ \\
Logarithmic & $\mathrm{MR}=a \times \exp \left(-k \times t^{n}\right)+b$ \\
\hline
\end{tabular}

PURELIN function was employed to the receiving neurons of the output layer to obtain the outcome of the ANN model, as follows:

$$
O_{o 1}=\lambda . O_{l 1} \sim O_{l 1} \text {. }
$$

The error between target and output of the selected backpropagation model was estimated and minimized to an acceptable level by adjusting the weights of the structure.

2.7. Estimation of Effective Moisture Diffusivity $\left(D_{\text {eff }}\right)$ and Activation Energy $\left(E_{a}\right)$. For the valuation of $D_{\text {eff, }}$ slab geometry was considered for pumpkin seeds, owing to its small thickness as related to other dimensions [35]. An assumption was made that negligible shrinkage due to drying took place with uniform distribution of initial MC. Fick's law was used to calculate $D_{\text {eff }}$ of pumpkin seeds [16], which was linearized as suggested by Golpour et al. [36]. Activation energy was determined using Arrhenius function, which expressed the relationship of $D_{\text {eff }}$ and temperature.

2.8. Mass Transfer Parameters. The parameters such as Biot number $\left(B_{i}\right)$ and mass transfer coefficient $\left(h_{m}\right)$ were determined by the equation given by Dincer and Hussain [37]. $B_{i}$, a dimensionless number, represents the correlation between internal and external convective heat transfer [38]. It also specifies the resistance of moisture transfer inside a product and is affected by the drying medium and product type. $B_{i}$ was calculated as

$$
B_{i}=\frac{24.848}{D_{i}^{0.375}}
$$

The relationship between air velocity and heating and cooling coefficient is provided by the Dincer number $\left(D_{i}\right)$. $D_{i}$ was expressed using

$$
D_{i}=\frac{v}{k H}
$$

Additionally, the convective mass transfer coefficient was determined using the following equation:

$$
B_{i}=\frac{h_{m} H}{D_{\text {eff }}},
$$

where $v$ is the air velocity, $\mathrm{m} / \mathrm{s} ; H$ is the thickness of the seed, $m$, and $k$ is the drying constant (taken from the best-fitted model). 


\section{Results and Discussion}

3.1. Drying Characteristics. The initial moisture content of pumpkin seeds was determined as $1.52 \pm 0.013 \mathrm{~kg} \mathrm{H}_{2} \mathrm{O} / \mathrm{kg}$ dry matter which reduced to $0.08 \pm 0.01 \mathrm{~kg} \mathrm{H}_{2} \mathrm{O} / \mathrm{kg}$ dry matter. The drying curves of dried pumpkin seeds in VFBD at different temperatures are shown in Figure 2. The reduction of moisture content of pumpkin seeds with time was observed at all drying conditions, as shown in Figure 2(a). A decrease in moisture content showed that diffusion mechanism was regulated by mass transfer within seeds (Ashtiani et al.) [39]. From Figure 2(b), it was observed that there was no constant rate period; this might be due to the thin-layer drying of pumpkin seed, which was unable to deliver a constant supply of moisture while drying. As drying proceeds, the free surface moisture evaporates and when surface moisture is insufficient, moisture diffusion takes place from the core of the seeds to the surface which also explained the decrease in MR, as observed in Figure 2(c). Therefore, a reduction of drying rate was observed with time with the initiation of falling rate. Another possible reason for faster moisture diffusion from pumpkin seeds could be its flat geometry exhibiting large surface-to-volume ratio. The migration of water from larger surfaces to its surrounding is much faster than in smaller surface seeds.

The drying rate was found to increase from 0.0063 to $0.0091 \mathrm{~kg} \mathrm{H} \mathrm{H}_{2} \mathrm{O} / \mathrm{kg} \mathrm{dm}$. min with the rise in temperature from 40 to $60^{\circ} \mathrm{C}$. It showed that elevated temperature elevates heat transfer gradient between surrounding air and seeds, which stimulates a higher drying rate and subsequently reduces drying time [40]. Similar results of drying curves were found in castor oil seeds (Ricinus communis) [31], watermelon seeds [41], pumpkin seeds [17], Jatropha curcas L. seeds [42], and garlic clove [43, 44]. Stakić and Urošević [45] dried poppy seeds in VFBD and reported that with the rise of temperature, the drying rate improved and drying time reduced. Lima et al. [46] also concluded that proper moisture evaporation and homogeneity were obtained in vibro-fluidized bed drying than conventional fluidized bed drying.

3.2. Mathematical Modeling. The results of experimental data were fitted to semiempirical models and the model coefficients were determined and are presented in Table 4. The best-fitted model was selected based on the maximum $R^{2}$ and lowest value of MSE and $\chi^{2}$. The range of $R^{2}$, MSE, and $\chi^{2}$ for all experiments were 0.9923 to $0.9990,7.55 \times 10^{-5}$ to $7.77 \times 10^{-4}$, and $8.48 \times 10^{-5}$ to $6.48 \times 10^{-4}$, respectively. The experimental data was fitted well in all the models with $R^{2}$ greater than 0.99. But the two-term model was fitted exceptionally well with the highest $R^{2}-0.999$, and lowest $\chi^{2}-1.03 \times 10^{-4}$ and MSE $7.55 \times 10^{-5}$ at a temperature of $60^{\circ} \mathrm{C}$. The validation of the best-fit model (i.e., two-term) was also conducted using MATLAB curve fitting tool. The goodness of validation as predicted parameters are SSE: 0.00113 and RMSE: 0.00870 . It was observed that drying rate constant $(k)$ was significantly $(p<0.05)$ improved with the rise of temperature. The residual plots for moisture ratio are presented in Figure 3(b). Heteroscedasticity of residual plot was observed for best-fitted model, which showed that the model prediction is good, and the data quality is high. Generally, heteroscedasticity of residual is expected for nonlinear regression models.

3.3. ANN Performance. ANN model was successfully trained by TRAINLM algorithm with 10 neurons in the HL. The correlation coefficients $(R)$ of ANN model for training, testing, and validation were 0.9999, 0.9997, and 0.9999, respectively, with a mean square error of $2.12 \times 10^{-4}$ as shown in Figure 4. The weights and bias of the final ANN topography for pumpkin seed drying in VFBD are shown in Table 5.

The predicted moisture content $\left(R^{2}=0.9967\right.$; MSE $\left.=5.29 \times 10^{-5}\right)$ and moisture ratio $\left(R^{2}=0.9963\right.$; MSE $\left.=2.42 \times 410^{-5}\right)$ of optimum network structure (2-10-2 topology) was projected by TANSIGMOID as shown in Figure 5. Kaveh [35] found that the ANN model-FFBP provided the best extrapolation of moisture ratio $\left(R^{2}=0.9944\right)$ of squash seeds dried in an FBD. Jafari et al. [23] determined that FFBP network with TRAINLM, TANSIGMOID activation function, and 2-5-1 topology showed $R^{2}$ of 0.9996 and minimum MSE of $3.94 \times 10^{-5}$ for predicting the moisture ratio of onion dried in fluidized bed dryer. The reported work was similar to our findings for pumpkin seeds.

3.4. Comparative Assessment of Semiempirical and Artificial Neural Network Model. Two-term model was found to most adequately fit the experimental data with maximum $R^{2}$ and minimum MSE. Subsequently, the two-term model was selected for comparison with the ANN model. The comparative statistical indicators are presented in Table 6. ANN provided a relatively reasonable fit at all drying conditions, which was in the range of the maximum $R^{2}$ and minimum MSE values of the semiempirical model. This illustrates that ANN is more capable of correlating all external and internal variables and is more likely to provide accurate predictions at other unseen processing conditions $[22,23]$.

3.5. Moisture Diffusivity and Activation Energy. The $D_{\text {eff was }}$ estimated from the slope obtained from the graph presented in Figure 6(a) for VFBD. The values for the same are displayed in Table 7 . The outcomes illustrated that $D_{\text {eff }}$ values of pumpkin seeds changed from $1.12 \mathrm{va}^{-9} \pm 3.62 .610^{-10}$ to 2.28 to $10^{-9} \pm 1.43 .410^{-10} \mathrm{~m}^{2} / \mathrm{s}$ in the temperature range of 40 to $60^{\circ} \mathrm{C}$ in VFBD, respectively. The values attained in this analysis were within the range of food materials, which is usually in the range of $10^{-11}$ to $10^{-9} \mathrm{~m}^{2} / \mathrm{s}$ [47].

It was observed that the moisture diffusivity significantly $(p<0.05)$ improved with rise in temperature. As explained before, the increased temperature reduces external resistance of the boundary layer, which accelerates heat transfer between the surface and center part of the seeds. Due to high temperature, vapor pressure within the seeds increases which causes faster moisture migration to the surface, 


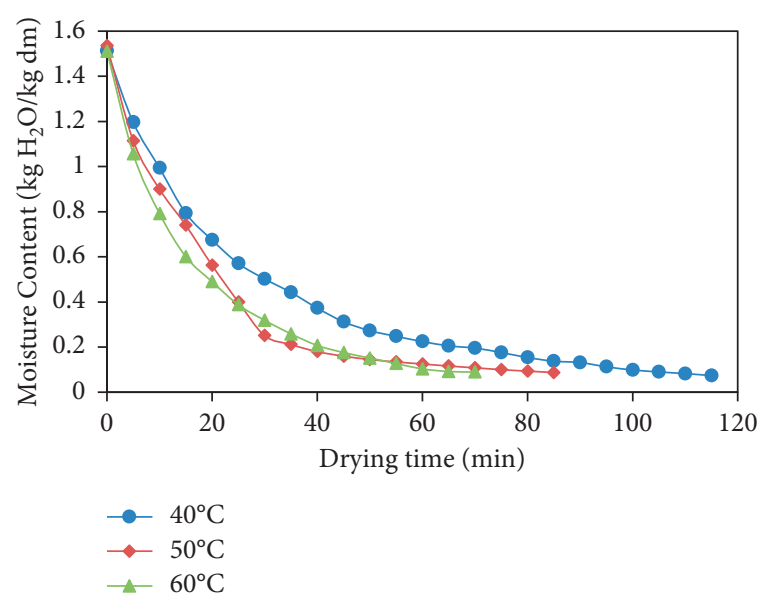

(a)

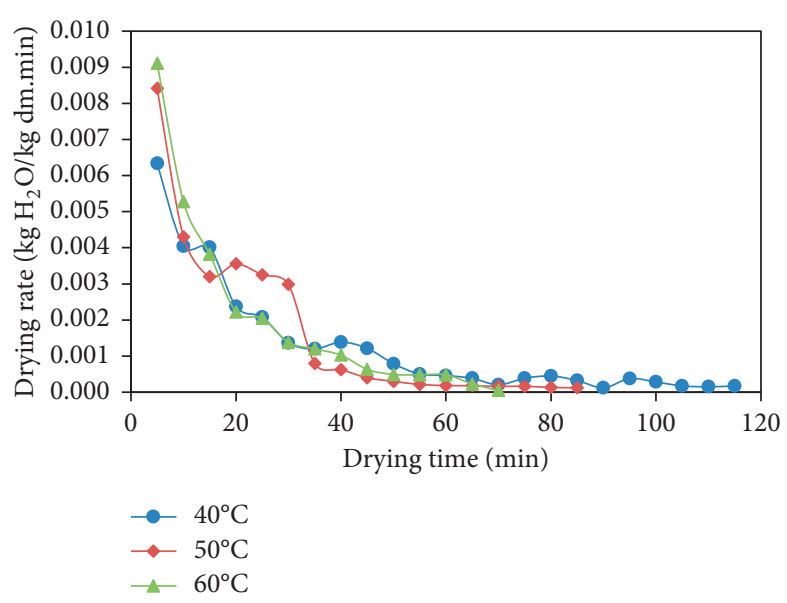

(b)

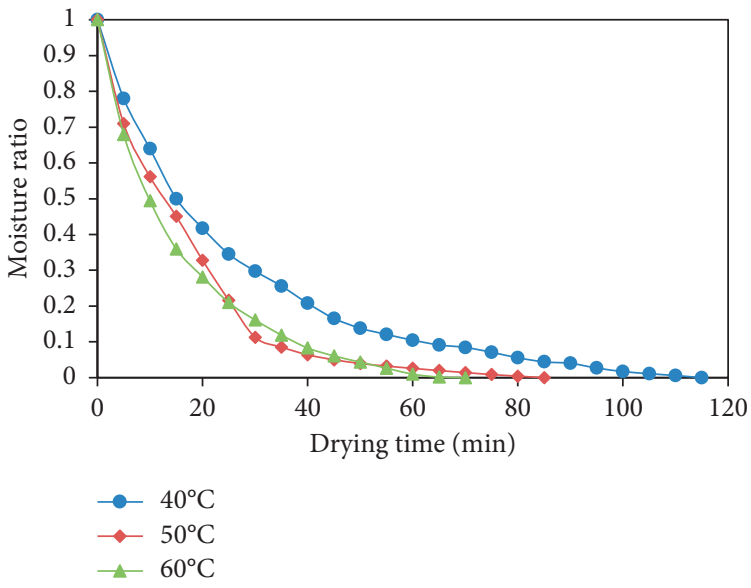

(c)

Figure 2: Drying characteristics of pumpkin seed in VFBD: change in (a) moisture content, (b) drying rate, and (c) moisture with drying time.

TABLE 4: Statistical parameters and the coefficients of pumpkin seeds dried in VFBD.

\begin{tabular}{|c|c|c|c|c|c|}
\hline Model & Temperature, ${ }^{\circ} \mathrm{C}$ & Empirical constants & $R^{2}$ & MSE & $x^{2}$ \\
\hline \multirow{4}{*}{ Two-term } & 40 & $\begin{array}{l}k=0.0397 \pm 0.0049, a=0.4842 \pm 0.0048 \\
b=0.4842 \pm 0.0049, k_{0}=0.0396 \pm 0.0013\end{array}$ & 0.9967 & $2.66 \times 10^{-4}$ & $2.72 \times 10^{-4}$ \\
\hline & 50 & $\begin{array}{c}k=0.0614 \pm 0.0009, a=0.5021 \pm 0.0078 \\
b=0.5021 \pm 0.0078, k_{0}=0.0614 \pm 0.0008\end{array}$ & 0.9949 & $4.88 \times 10^{-4}$ & $6.27 \times 10^{-4}$ \\
\hline & 60 & $\begin{array}{c}k=0.4405 \pm 0.3801, a=0.1014 \pm 0.0373 \\
b=0.8968 \pm 0.0 .036, k_{0}=0.0594 \pm 0.0019\end{array}$ & 0.9990 & $7.55 \times 10^{-5}$ & $1.03 \times 10^{-4}$ \\
\hline & 40 & $k=0.0410 \pm 6.63 \times 10^{-4}$ & 0.9956 & $3.00 \times 10^{-4}$ & $3.14 \times 10^{-4}$ \\
\hline \multirow[t]{3}{*}{ Newton } & 50 & $k=0.0611 \pm 0.0015$ & 0.9939 & $4.89 \times 10^{-4}$ & $5.18 \times 10^{-4}$ \\
\hline & 60 & $k=0.0657 \pm 0.0013$ & 0.9964 & $2.80 \times 10^{-4}$ & $3.00 \times 10^{-4}$ \\
\hline & 40 & $\begin{array}{c}k=0.0416 \pm 0.0012, a=0.9637 \pm 0.0011 \\
b=0.0136 \pm 0.0059\end{array}$ & 0.9972 & $2.36 \times 10^{-4}$ & $2.17 \times 10^{-4}$ \\
\hline \multirow[t]{3}{*}{ Logarithmic } & 50 & $\begin{aligned} k=0.0592 & \pm 0.0027, a=1.010 \pm 0.0215 \\
b & =-0.0109 \pm 0.0101\end{aligned}$ & 0.9943 & $4.51 \times 10^{-4}$ & $5.41 \times 10^{-4}$ \\
\hline & 60 & $\begin{aligned} k=0.06430 & \pm 0.0025, a=0.9746 \pm 0.015 \\
b & =0.0012 \pm 0.0088\end{aligned}$ & 0.9971 & $2.25 \times 10^{-4}$ & $2.81 \times 10^{-4}$ \\
\hline & 40 & $k=0.0252 \pm 3.38 \times 10^{-4} n=1 \pm 0$ & 0.9956 & $3.01 \times 10^{-4}$ & $3.28 \times 10^{-4}$ \\
\hline \multirow{2}{*}{ Modified page } & 50 & $k=0.0306 \pm 7.96 \times 10^{-4} n=1 \pm 0$ & 0.9939 & $4.88 \times 10^{-4}$ & $5.50 \times 10^{-4}$ \\
\hline & 60 & $k=0.0329 \pm 6.81 \times 10^{-4} n=1 \pm 0$ & 0.9964 & $2.79 \times 10^{-4}$ & $3.23 \times 10^{-4}$ \\
\hline
\end{tabular}


TABLE 4: Continued.

\begin{tabular}{lccccc}
\hline Model & Temperature, ${ }^{\circ} \mathrm{C}$ & Empirical constants & $R^{2}$ & MSE \\
\hline & 40 & $k=0.0578 \pm 0.0025, n=0.9000 \pm 0.012$ & 0.9989 & $7.77 \times 10^{-5}$ & $8.48 \times 10^{-5}$ \\
Page & 50 & $k=0.0503 \pm 0.007, n=1.064 \pm 0.044$ & 0.9947 & $4.24 \times 10^{-4}$ & $4.77 \times 10^{-4}$ \\
& 60 & $k=0.0856 \pm 0.0052, n=0.9111 \pm 0.0021$ & 0.9986 & $1.13 \times 10^{-4}$ & $1.30 \times 10^{-4}$ \\
& 40 & $k=0.0397 \pm 7.49 \times 10^{-4} a=0.9683 \pm 0.011$ & 0.9967 & $2.25 \times 10^{-4}$ & $2.48 \times 10^{-4}$ \\
Henderson and Pabis & 50 & $k=0.0615 \pm 0.0019, a=1.0046 \pm 0.0197$ & 0.9939 & $5.26 \times 10^{-4}$ & $5.49 \times 10^{-4}$ \\
& 60 & $k=0.0641 \pm 0.015, a=0.9752 \pm 0.015$ & 0.9971 & $2.36 \times 10^{-4}$ & $2.59 \times 10^{-4}$ \\
\hline
\end{tabular}

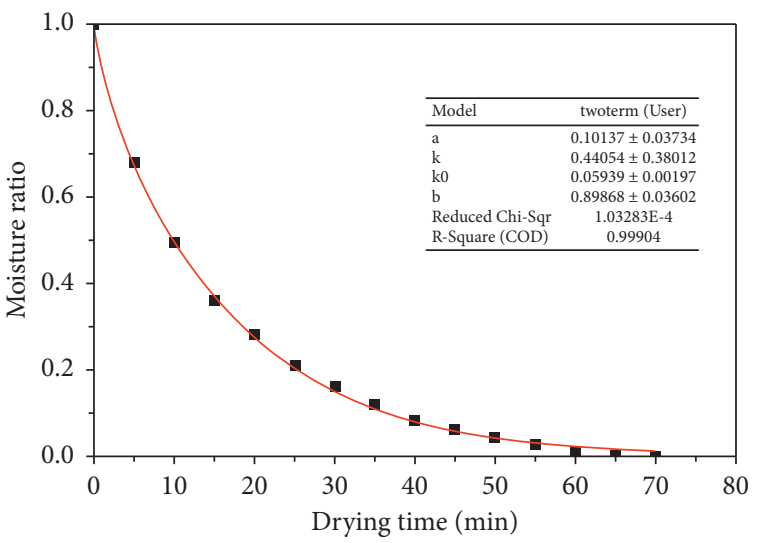

- Experimental MR

Two-term model (Predicted MR)

(a)

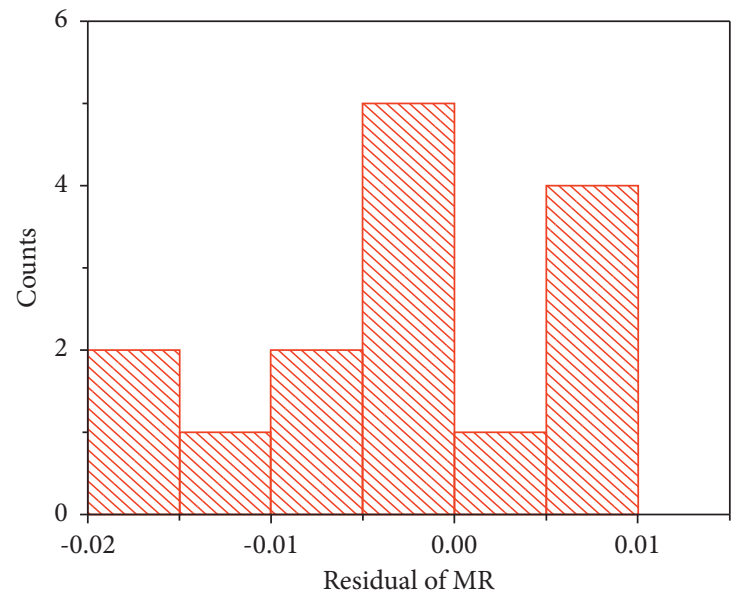

(c)

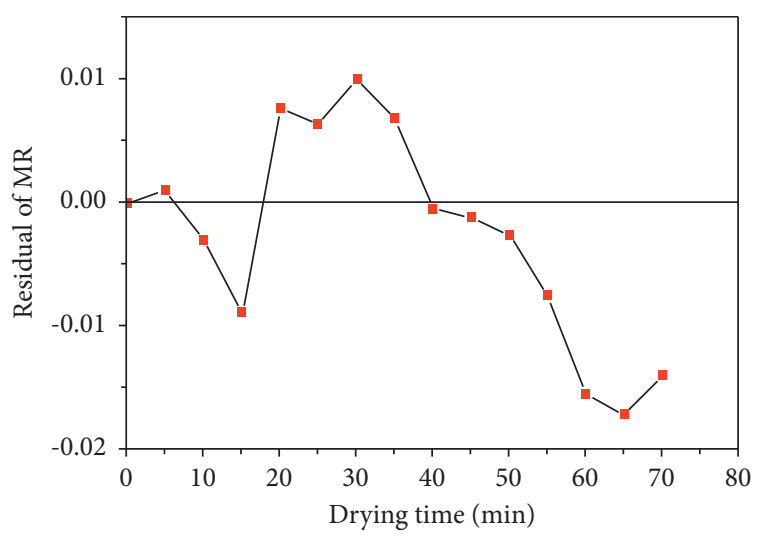

(b)

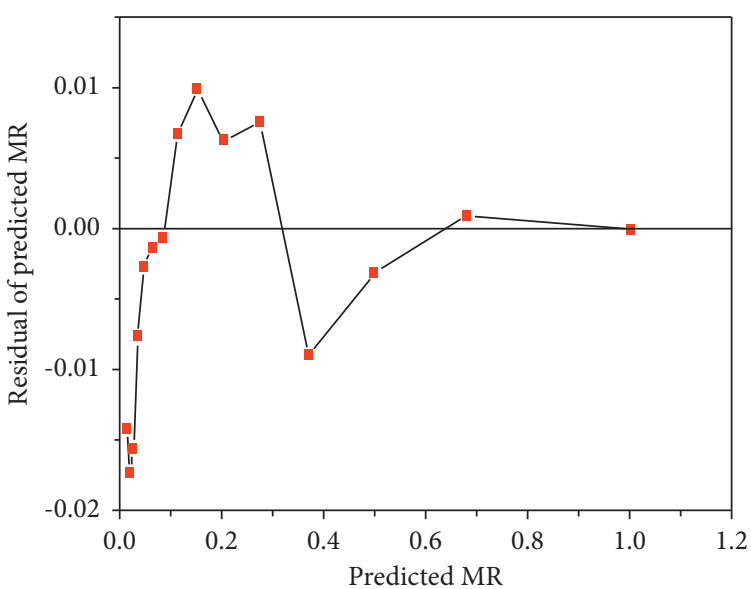

(d)

Figure 3: (a) Two-term model fitting plot. (b) Variation of residuals with time. (c) Normal probability plot of residuals. (d) Heteroscedasticity plot.

resulting in increased $D_{\text {eff. The diffusivity of different ma- }}$ terials depends on their structure, temperature, and moisture content [48].

The graphical representation of logarithmic moisture ratio $\ln D_{\text {eff }}$ versus $\mathrm{T}^{-1}$ for drying of pumpkin seed at the different temperatures is shown in Figure 6(b) for VFBD. $E_{a}$ of pumpkin seeds was determined as $32.71 \pm 1.05 \mathrm{~kJ} / \mathrm{mol}$ in VFBD. According to Bezerra et al. [49], if $E_{a}$ is greater, the evaporation of moisture from the surface of the sample is slower due to strongly bonded moisture with other compounds. The value of
$E_{a}$ found in this report was within the range of $E_{a}$ obtained for food products and low as compared to values reported in previous studies $[18,19]$.

3.6. Mass Transfer Parameters. $B_{i}$ represents the rate of moisture diffusion during the process of drying. The $B_{i}$ and $h_{m}$ values are summarized in Table 7 . As expected, the $B_{i}$ number and $h_{m}$ were significantly $(p<0.05)$ increased from $0.51 \pm 0.01$ to $0.60 \pm 0.01$, and $2.42 .010^{-7} \pm 9.24 .210^{-8}$ to 

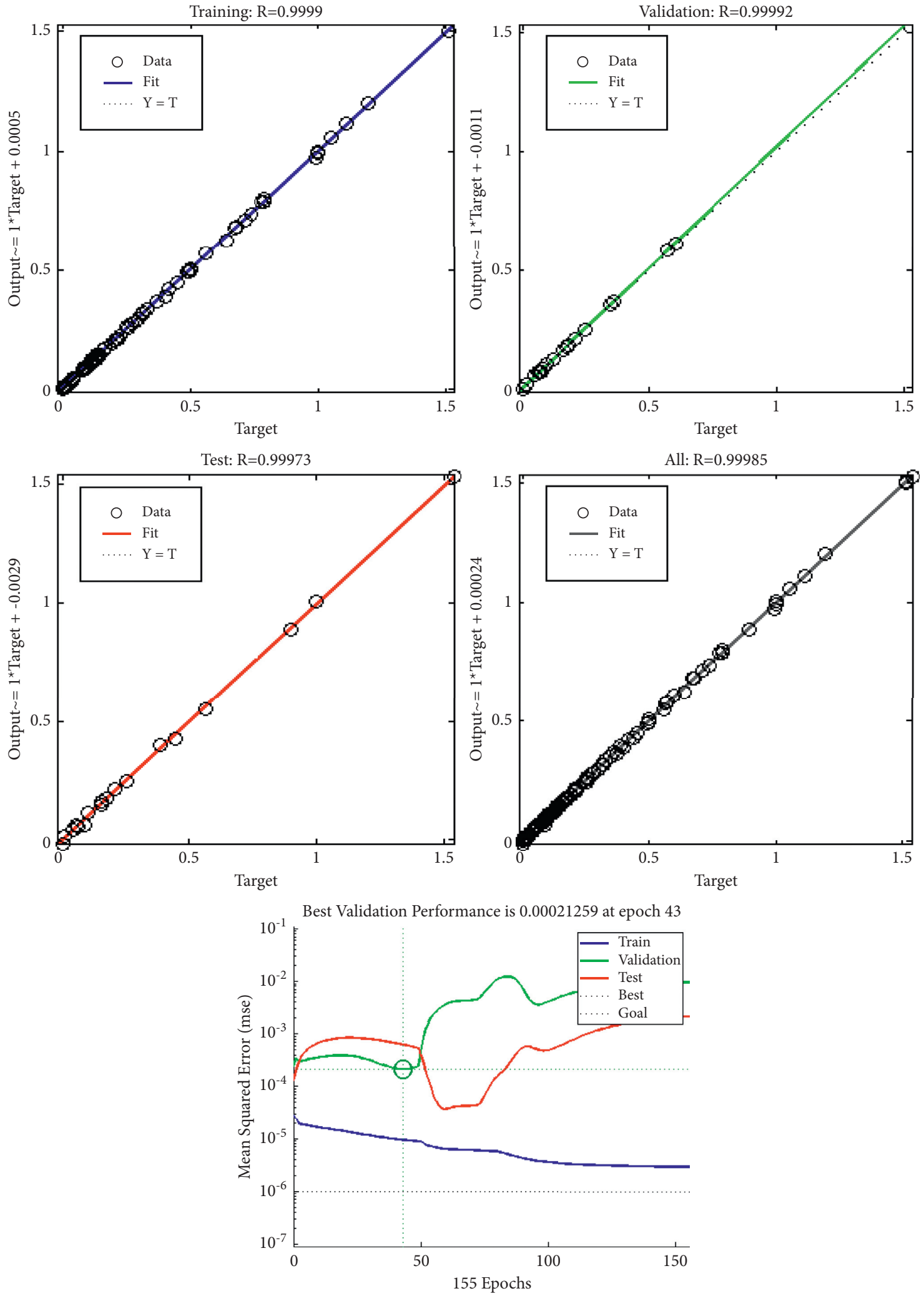

FIGURE 4: Training performance of the generated neural network with 2 inputs (temperature and drying time), 10 hidden layer neurons, and 2 outputs (moisture content and moisture ratio).

7.45 to $10^{-7} \pm 5.52 .510^{-8} \mathrm{~m} / \mathrm{s}$, respectively, with the increase of temperature from $40^{\circ} \mathrm{C}$ to $60^{\circ} \mathrm{C}$. $B_{i}$ can be classified as follows: $B_{i}<0.1 ; 0.1<B_{i}<100$; and $B_{i}>100$. If $B_{i}<0.1$, then there is less internal resistance and more exterior resistance to moisture diffusion through fluid boundary layer within a product. If $0.1<B_{i}<100$, it specifies that 
TABLE 5: Weights and biases for the obtained neural network.

\begin{tabular}{|c|c|c|c|c|c|c|}
\hline \multirow{2}{*}{$j, k$} & \multicolumn{4}{|c|}{ Weights } & \multicolumn{2}{|c|}{ Bias } \\
\hline & $w_{1 j}$ & $w_{2 j}$ & $w_{j 1}$ & $w_{j 2}$ & $b_{j}$ & $b_{k}$ \\
\hline 1 & 3.4253 & -2.6199 & 0.3718 & 0.3905 & -4.959 & 2.1745 \\
\hline 2 & 3.3791 & 5.0788 & 0.8209 & 0.8345 & -5.0407 & 2.2252 \\
\hline 3 & -5.4467 & 6.1391 & -0.61 & -0.6045 & 3.7684 & - \\
\hline 4 & 4.4125 & -2.2221 & -0.6507 & -0.6479 & -1.7083 & - \\
\hline 5 & 0.5999 & 3.3198 & -0.0667 & -0.0666 & -1.105 & - \\
\hline 6 & -5.3801 & -3.3426 & 0.2788 & 0.2695 & -0.8644 & - \\
\hline 7 & -4.0007 & -1.7235 & -0.2726 & -0.2522 & -0.8594 & - \\
\hline 8 & 0.1321 & 4.0858 & -3.5083 & -3.5636 & 4.7189 & - \\
\hline 9 & 3.6053 & 2.1813 & -0.4538 & -0.4614 & 4.7392 & - \\
\hline 10 & 1.7939 & 4.7844 & 2.0048 & 2.0376 & 7.2173 & - \\
\hline
\end{tabular}

$w$ : weight, $b$ : bias, $i$ : input layer node, $j$ : hidden layer node, and $k$ : output layer node.
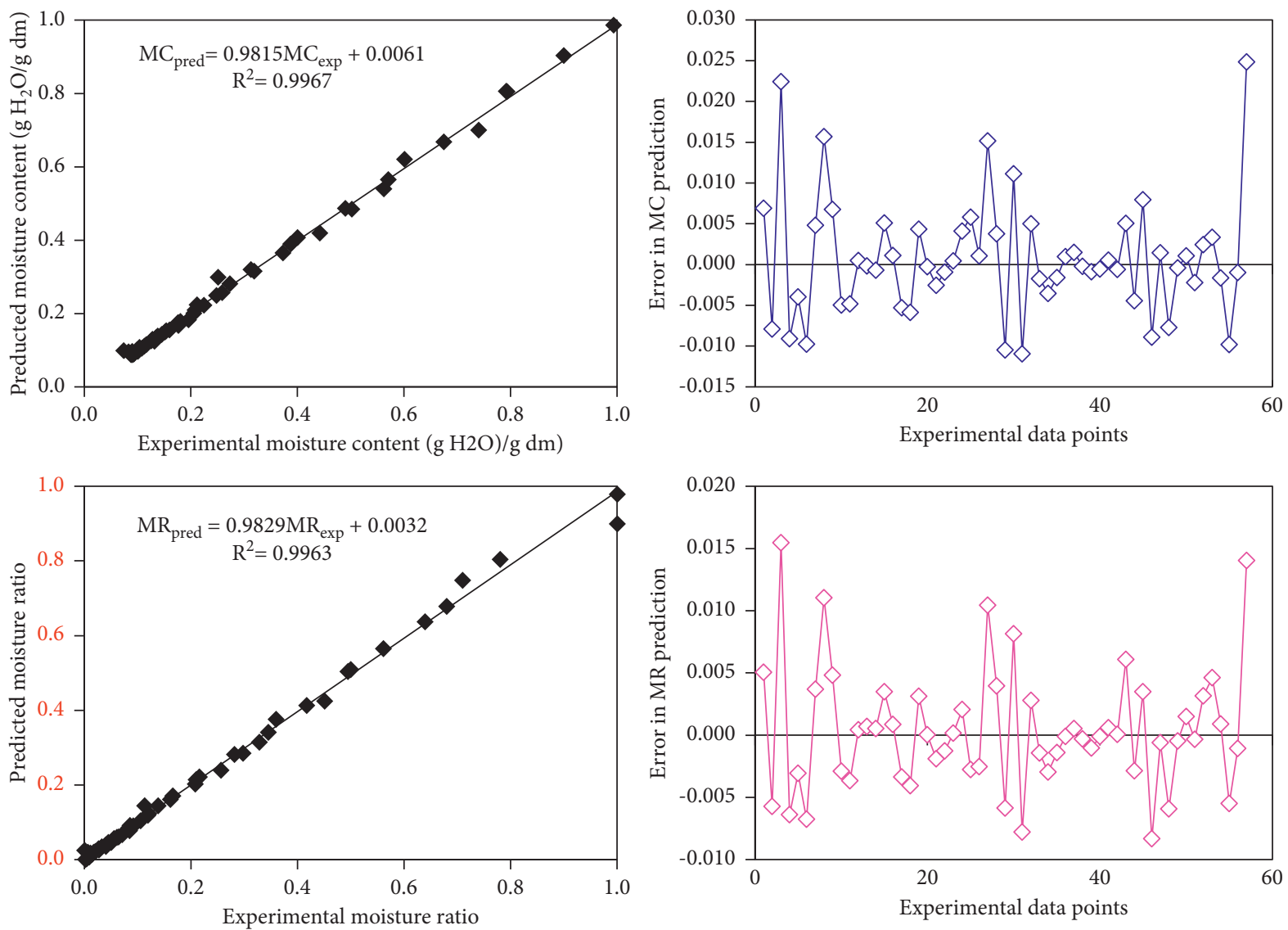

FIGURE 5: Simulated performance of the generated neural network along with error variation graph showing ANN learning (random error indicates proper training).

TABLE 6: Comparative analysis of semiempirical and ANN model.

\begin{tabular}{lcc}
\hline Model & $R^{2}$ & MSE \\
\hline Two-term & $0.9949-0.9990$ & $1.03 \times 10^{-4}-6.27 \times 10^{-4}$ \\
ANN & 0.9963 & $2.42 \times 10^{-5}$ \\
\hline
\end{tabular}

there is presence of both internal and exterior resistance, and if $B_{i}>100$, it suggests maximum internal and very less external resistance to the moisture diffusion with the product due to drying [50]. The values of $B_{i}$ in the present investigation lies in the second category, which reveals the existence of both internal and external resistance to moisture removal. The rise in accessible thermal energy in food material due to elevated temperature stimulates the water molecules, which causes a high rate of mass transfer [51]. Similar trends were observed in cocoyam dried in a convective dryer [52], in apples (cv. Golden Delicious) dried in a vacuum drying with the temperature escalated from $50^{\circ} \mathrm{C}$ to $70^{\circ} \mathrm{C}$ [53], and moringa leaves vacuum-dried in the range of $40^{\circ} \mathrm{C}$ to $60^{\circ} \mathrm{C}[22]$. 


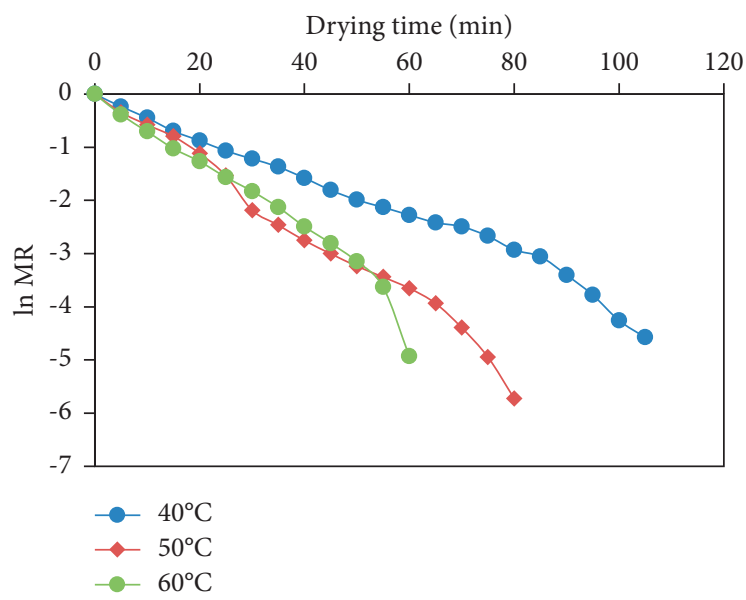

(a)

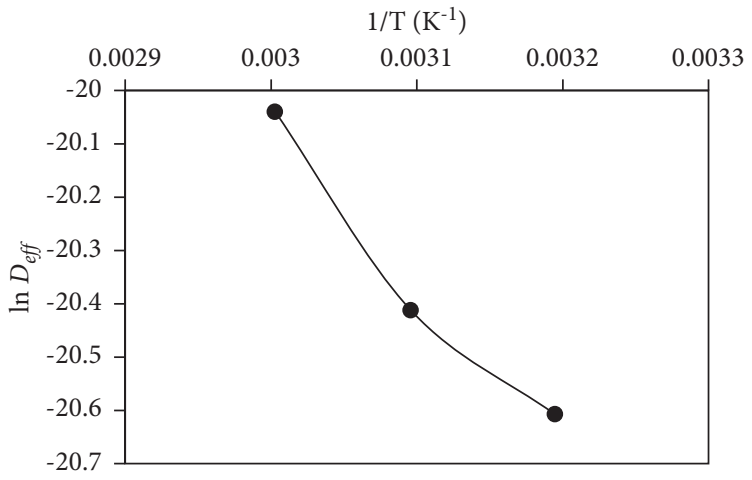

(b)

Figure 6: (a) Experimental ln MR with time at different temperatures. (b) Plot for determination of activation energy.

TABLE 7: $D_{\text {eff, }} E_{a}$, and mass transfer constraints of pumpkin seeds at different drying temperatures.

\begin{tabular}{lccccc}
\hline Temperature $\left({ }^{\circ} \mathrm{C}\right)$ & $D_{\text {eff }}\left(\mathrm{m}^{2} / \mathrm{s}\right)$ & $E_{a}(\mathrm{~kJ} / \mathrm{mol})$ & $k$ & $B_{i}$ & $h_{m}(\mathrm{~m} / \mathrm{s})$ \\
\hline 40 & $1.12 \pm 3.62 \times 10^{-10}$ & & $0.04 \pm 0.00$ & $0.51 \pm 0.01$ & $1.49 \pm 4.89 \times 10^{-8}$ \\
50 & $1.55 \pm 6.7 \times 10^{-11}$ & $32.71 \pm 1.05$ & $0.064 \pm 0.00$ & $0.60 \pm 0.01$ & $2.42 \pm 9.24 \times 10^{-8}$ \\
60 & $2.28 \pm 1.43 \times 10^{-10}$ & & $0.44 \pm 0.01$ & $1.26 \pm 0.01$ & $7.45 \pm 5.52 \times 10^{-8}$ \\
\hline
\end{tabular}

\section{Conclusions}

Pumpkin seeds were dried in a VFBD at 40,50 , and $60^{\circ} \mathrm{C}$ at a constant air velocity of $4 \mathrm{~m} / \mathrm{s}$ with $4.26(A=10 \mathrm{~mm}$ and $f=10.3 \mathrm{~Hz}$ ) vibration intensity. It was noted that air temperature significantly influenced the drying characteristics of pumpkin seeds. Among all six semiempirical models, the twoterm model fitted more precisely to investigational data with maximum $R^{2}-0.999$, and lowest $\chi^{2}-1.03 \times 10^{-4}$ and MSE $7.55 \times 10^{-5}$. A comparative assessment between the predicted two-term model and ANN was performed. ANN gave a better overall prediction for the drying characteristics in terms of statistical indicators. The value of $D_{\text {eff }}, B_{i}$, and $h_{m}$ of pumpkin seeds increased with the increase in drying temperature. Activation energy calculated from the Arrhenius equation shows that a moderate amount of energy; that is, $32.71 \pm 1.05 \mathrm{~kJ} / \mathrm{mol}$ is essential to start the drying. Drying of pumpkin seeds at $60^{\circ} \mathrm{C}$ for $1.15 \mathrm{~h}$ in VFBD is suggested at $4 \mathrm{~m} / \mathrm{s}$ air velocity with a vibration intensity of 4.26 .

\section{Data Availability}

All data pertaining to this work are available within the manuscript.

\section{Conflicts of Interest}

The authors declare that there are no conflicts of interest.

\section{Acknowledgments}

The authors are thankful to members of the Department of Food Engineering, NIFTEM (Sonipat), for their facilities, support, and encouragement. The first author thanks the Ministry of Tribal Affairs, Government of India, for providing fellowship vide Grant no. 201718-NFST-MAH02452 .

\section{References}

[1] FAO, "FAOSTAT," FAO, Rome, Italy, 2018, http://www.fao. org/home/en/.

[2] X. Rico, B. Gullón, J. Luis Alonso, and R. Yáñez, "Recovery of high value-added compounds from pineapple, melon, watermelon and pumpkin processing by-products: an overview," Food Research International, vol. 132, pp. 1-21, 2020.

[3] J. F. Ayala-Zavala, V. Vega-Vega, C. Rosas-Domínguez et al., "Agro-industrial potential of exotic fruit byproducts as a source of food additives," Food Research International, vol. 44, no. 7, pp. 1866-1874, 2011.

[4] R. P. Cuco, L. Cardozo-Filho, and C. d. Silva, "Simultaneous extraction of seed oil and active compounds from peel of pumpkin (cucurbita maxima) using pressurized carbon dioxide as solvent," The Journal of Supercritical Fluids, vol. 143, pp. 8-15, 2019.

[5] P. G. Peiretti, G. Meineri, F. Gai, E. Longato, and R. Amarowicz, "Antioxidative activities and phenolic compounds of pumpkin (cucurbita pepo) seeds and amaranth (amaranthus caudatus) grain extracts," Natural Product Research, vol. 31, no. 18, pp. 2178-2182, 2017.

[6] A. Can, "An analytical method for determining the temperature dependent moisture diffusivities of pumpkin seeds during drying process," Applied Thermal Engineering, vol. 27, no. 2-3, pp. 682-687, 2007.

[7] M. Kaveh, V. Rasooli, and R. Amiri, "ANFIS and ANNs model for prediction of moisture diffusivity and specific energy consumption potato, garlic and cantaloupe drying under 
convective hot air dryer," Information Processing in Agriculture, vol. 5, no. 3, pp. 372-387, 2018.

[8] N. D. Mrad, N. Boudhrioua, N. Kechaou, F. Courtois, and C. Bonazzi, "Influence of air drying temperature on kinetics, physicochemical properties, total phenolic content and ascorbic acid of pears," Food and Bioproducts Processing, vol. 90, no. 3, pp. 433-441, 2012.

[9] A. S. Mujumdar, "Research and development in drying: recent trends and future prospects," Drying Technology, vol. 22, no. 1-2, pp. 1-26, 2004.

[10] S. Soponronnarit, S. Wetchacama, S. Trutassanawin, and W. Jariyatontivait, "Design, testing, and optimization of vibro-fluidized bed paddy dryer," Drying Technology, vol. 19, no. 8, pp. 1891-1908, 2001.

[11] D. Jia, O. Cathary, J. Peng et al., "Fluidization and drying of biomass particles in a vibrating fluidized bed with pulsed gas flow," Fuel Processing Technology, vol. 138, pp. 471-482, 2015.

[12] R. V. Daleffe, M. C. Ferreira, and J. T. Freire, "Drying of pastes in vibro-fluidized beds: effects of the amplitude and frequency of vibration," Drying Technology, vol. 23, no. 9-11, pp. 1765-1781, 2005.

[13] L. Meili, F. B. Freire, M. do Carmo Ferreira, and J. T. Freire, "Fluid dynamics of vibrofluidized beds during the transient period of water evaporation and drying of solutions," Chemical Engineering \& Technology, vol. 35, no. 10, pp. 1803-1809, 2012.

[14] O. A. Babar, A. Tarafdar, S. Malakar, K. Arora, and P. K. Nema, "Design and performance evaluation of a passive flat plate collector solar dryer for agricultural products." Journal of Food Process Engineering, vol. 43, no. 10, Article ID e13484, 2020.

[15] A. Sander, "Thin-layer drying of porous materials: selection of the appropriate mathematical model and relationships between thin-layer models parameters," Chemical Engineering and Processing: Process Intensification, vol. 46, no. 12, pp. 1324-1331, 2007.

[16] K. Sacilik, "Effect of drying methods on thin-layer drying characteristics of hull-less seed pumpkin (cucurbita pepo L.)," Journal of Food Engineering, vol. 79, no. 1, pp. 23-30, 2007.

[17] Z. Uddin, P. Suppakul, and W. Boonsupthip, "Effect of air temperature and velocity on moisture diffusivity in relation to physical and sensory quality of dried pumpkin seeds," Drying Technology, vol. 34, no. 12, pp. 1423-1433, 2016.

[18] R. A. Chayjan, K. Salari, Q. Abedi, and A. A. Sabziparvar, "Modeling moisture diffusivity, activation energy and specific energy consumption of squash seeds in a semi fluidized and fluidized bed drying," Journal of Food Science \& Technology, vol. 50, no. 4, pp. 667-677, 2013.

[19] W. Jittanit, "Kinetics and temperature dependent moisture diffusivities of pumpkin seeds during drying," Kasetsart Journal-Natural Science, vol. 45, no. 1, pp. 147-158, 2011.

[20] S. Mujaffar and S. Ramsumair, "Fluidized bed drying of pumpkin (cucurbita sp.) seeds," Foods, vol. 8, no. 147, pp. 1-13, 2019.

[21] I. Doymaz, "Experimental study on drying characteristics of pumpkin seeds in an infrared dryer," Latin American Applied Research, vol. 46, pp. 169-174, 2016.

[22] A. Tarafdar, N. Jothi, and B. P. Kaur, "Mathematical and artificial neural network modeling for vacuum drying kinetics of moringa olifera leaves followed by determination of energy consumption and mass transfer parameters," Journal of Applied Research on Medicinal and Aromatic Plants, vol. 24, Article ID 100306, 2021.

[23] M. G. Jafari, D. Dehnad, and V. Ghanbari, "Mathematical, fuzzy logic and artificial neural network modeling techniques to predict drying kinetics of onion," Journal of Food Processing and Preservation, vol. 40, no. 2, pp. 329-339, 2016.

[24] M. Kaveh, R. A. Chayjan, I. Golpour, S. Poncet, F. Seirafi, and B. Khezri, "Evaluation of exergy performance and onion drying properties in a multi-stage semi-industrial continuous dryer: artificial neural networks (ANNs) and ANFIS models," Food and Bioproducts Processing, vol. 127, pp. 58-76, 2021.

[25] E. Taghinezhad, M. Kaveh, E. Khalife, and G. Chen, "Drying of organic blackberry in combined hot air-infrared dryer with ultrasound pretreatment," Drying Technology, vol. 39, no. 14, pp. 1-17, 2020.

[26] P. I. Alvarez, R. Blasco, J. Gomez, and F. A. Cubillos, “A first principles-neural networks approach to model a vibrated fluidized bed dryer: simulations and experimental results," Drying Technology, vol. 23, no. 1-2, pp. 187-203, 2005.

[27] D. Kumar, A. Tarafdar, Y. Kumar, and P. C. Badgujar, "Intelligent modeling and detailed analysis of drying, hydration, thermal, and spectral characteristics for convective drying of chicken breast slices," Journal of Food Process Engineering, vol. 42 , no. 5, pp. 1-14, 2019.

[28] AOAC, AOAC Official Methods of Analysis, Association of Official Analytical Chemists, Arlington, TX, USA, 15th edition, 1990.

[29] H. Perazzini, F. Bentes Freire, and J. Teixeira Freire, "The influence of vibrational acceleration on drying kinetics in vibro-fluidized bed," Chemical Engineering and Processing: Process Intensification, vol. 118, no. 4, pp. 124-130, 2017.

[30] Z. Pakowski, A. S. Mujumdar, and C. Strumillo, "Theory and application of vibrated beds and vibrated fluid beds for drying processes," Advances in Drying, vol. 3, pp. 245-306, 1984.

[31] M. J. Perea-Flores, V. Garibay-Febles, J. J. Chanona-Pérez et al., "Mathematical modelling of castor oil seeds (ricinus communis) drying kinetics in fluidized bed at high temperatures," Industrial Crops and Products, vol. 38, no. 1, pp. 64-71, 2012.

[32] D. Zare, H. Naderi, and M. Ranjbaran, "Energy and quality attributes of combined hot-air/infrared drying of paddy," Drying Technology, vol. 33, no. 5, pp. 570-582, 2015.

[33] A. Tarafdar, N. Chandra Shahi, and A. Singh, "Freeze-drying behaviour prediction of button mushrooms using artificial neural network and comparison with semi-empirical models," Neural Computing \& Applications, vol. 31, no. 11, pp. 72577268, 2018.

[34] M. Dorofki, A. H. Elshafie, O. Jaafar, O. A. Karim, and S. Mastura, "Comparison of artificial neural network transfer functions abilities to simulate extreme runoff data," in Proceedings of the 2012 International Conference on Environment, Energy and Biotechnology, pp. 39-44, Kuala Lumpur, Malaysia, May 2012.

[35] M. Kaveh, "Modeling drying properties of pistachio nuts, squash and cantaloupe seeds under fixed and fluidized bed using data-driven models and artificial neural networks," DEGRUYTER International Journal of Food Engineering, vol. 24, no. 1, pp. 1-19, 2018.

[36] I. Golpour, M. Z. Nejad, R. A. Chayjan, and A. M. Nikbakht, R. P. F. Guiné and M. Dowlati, "Investigating shrinkage and moisture diffusivity of melon seed in a microwave assisted thin layer fluidized bed dryer," Journal of Food Measurement and Characterization, vol. 11, no. 1, pp. 1-11, 2017.

[37] I. Dincer and M. M. Hussain, "Development of a new bi-di correlation for solids drying," International Journal of Heat and Mass Transfer, vol. 45, no. 15, pp. 3065-3069, 2002.

[38] S. Şevik, M. Aktaş, E. Can, E. Arslan, and A. Doğuş, "Performance analysis of solar and solar-infrared dryer of mint 
and apple slices using energy-exergy methodology," Solar Energy, vol. 180, pp. 537-549, 2019.

[39] M. Ashtiani, S. Hassan, A. Salarikia, and M. R. Golzarian, "Analyzing drying characteristics and modeling of thin layers of peppermint leaves under hot-air and infrared treatments," Information Processing in Agriculture, vol. 4, no. 2, pp. 128139, 2017.

[40] J. Mitra, S. L. Shrivastava, and P. Srinivasa Rao, "Vacuum dehydration kinetics of onion slices," Food and Bioproducts Processing, vol. 89, no. 1, pp. 1-9, 2011.

[41] I. Doymaz, "Experimental study and mathematical modeling of thin-layer infrared drying of watermelon seeds," Journal of Food Processing and Preservation, vol. 38, no. 3, pp. 13771384, 2014.

[42] Y. G. Keneni, A. K. Trine Hvoslef-Eide, and J. M. Marchetti, "Mathematical modelling of the drying kinetics of Jatropha curcas L. seeds," Industrial Crops and Products, vol. 132, pp. 12-20, 2019.

[43] S. Malakar and V. K. Arora, "Mathematical modeling of drying kinetics of garlic clove in forced convection evacuated tube solar dryer," Lecture Notes In Mechanical Engineering, Springer, Berlin, Germany, pp. 813-820, 2021.

[44] S. Malakar, V. K. Arora, and P. K. Nema, "Design and performance evaluation of an evacuated tube solar dryer for drying garlic clove," Renewable Energy, vol. 168, pp. 568-580, 2021.

[45] M. Stakić and T. Urošević, "Experimental study and simulation of vibrated fluidized bed drying," Chemical Engineering and Processing: Process Intensification, vol. 50, no. 4, pp. $428-437,2011$.

[46] R. A. B. Lima, A. S. Andrade, and M. F. G. Fernandes, J. T. Freire and M. C. Ferreira, "Thin-layer and vibrofluidized drying of basil leaves (ocimum basilicum L.): analysis of drying homogeneity and influence of drying conditions on the composition of essential oil and leaf colour," Journal of Applied Research on Medicinal and Aromatic Plants, vol. 7, pp. 54-63, 2017.

[47] H. Li, L. Xie, M. Yue, M. Zhang, Y. Zhao, and X. Zhao, "Effects of drying methods on drying characteristics, physicochemical properties and antioxidant capacity of okra," LWT-Food Science and Technology, vol. 101, no. 11, pp. 630-638, 2019.

[48] Z. Erbay and F. Icier, "A review of thin layer drying of foods: theory, modeling, and experimental results," Critical Reviews in Food Science and Nutrition, vol. 50, no. 5, pp. 441-464, 2010.

[49] C. V. Bezerra, L. H. Meller da Silva, D. F. Corrêa, A. M. C. Rodrigues, M. Antonio, and C. Rodrigues, "A modeling study for moisture diffusivities and moisture transfer coefficients in drying of passion fruit peel," International Journal of Heat and Mass Transfer, vol. 85, pp. 750-755, 2015.

[50] I. Dincer, "Moisture transfer analysis during drying of slab woods," Heat and Mass Transfer, vol. 34, no. 4, pp. 317-320, 1998.

[51] H. Darvishi, Z. Farhudi, and N. Behroozi-Khazaei, "Mass transfer parameters and modeling of hot air drying kinetics of dill leaves," Chemical Product and Process Modeling, vol. 12, no. 2, pp. 1-12, 2017.

[52] M. C. Ndukwu, C. Dirioha, F. I. Abam, and V. E. Ihediwa, "Heat and mass transfer parameters in the drying of cocoyam slice," Case Studies in Thermal Engineering, vol. 9, pp. 62-71, 2017.

[53] F. Nadi and D. Tzempelikos, "Vacuum drying of apples (cv. golden delicious): drying characteristics, thermodynamic properties, and mass transfer parameters," Heat and Mass Transfer, vol. 54, no. 7, pp. 1853-1866, 2018. 